\title{
La potestad judicial del Obispo en el M. Pr. Mitis ludex
}

\section{The Judicial Power of the Bishop in Motu Proprio Mitis ludex}

\section{Jorge HORTA ESPINOZA, OFM}

Profesor Extraordinario de Derecho Canónico Pontificia Università Antonianum. Roma jhorta63@hotmail.com
Resumen: La presente relación analiza la figura del Obispo en su calidad de juez, a la luz del motu proprio Mitis ludex Dominus lesus, promulgado por Papa Francisco el 15 de agosto del 2015. El análisis se desarrolla en cuatro aspectos esenciales: 1. la reciente normativa ¿es novedad o redescubrimiento?; 2. precedentes históricos; 3. exigencias de la nueva normativa; 4. problemáticas y desafíos. Los dos primeros aspectos sientan las bases de la reflexión, los dos siguientes precisan sea el ámbito aplicativo de la norma como también los desafíos de su actuación. En efecto, el último punto se propone como una «vía inconclusa» o como una «conclusión abierta» en cuanto las respuestas deseadas surgirán en modo contemporáneo a la experiencia de los Obispos-Jueces en su actividad judicial y en la aplicación de la norma contenida en el motu proprio.

Palabras clave: Obispo, Juez, Mitis ludex Dominus lesus.
Abstract: This paper analyses the role of the bishop as judge in light of Motu Proprio Mitis ludex Dominus lesus, promulgated by Pope Francis on 15 August 2015. The analysis addresses these four main issues: 1. is the normative character of the text an innovation or a rediscovery? 2. the historical background; 3 . the requirements of the new legislation; and 4. problematic issues and challenges. The first two points lay the groundwork for further consideration, while the latter two aim to clarify the scope of the legislation and highlight potential challenges in its application. Indeed, the final point is framed as an «open conclusion», as responses may be expected to arise through both the experience of Bishop-Judges in carrying out their juridical role and in the application of the legislation contained in the Motu Proprio.

Keywords: Bishop, Judge, Mitis ludex Dominus lesus. 
$E$ s muy probable que la normativa contenida en el Motu proprio Mitis Iudex Dominus Iesus haya provocado en algunos estupor y maravilla, en otros confusión e incluso molestia. Y esto a pesar que algunas de sus resoluciones se esperaban o intuían, sea por las discusiones realizadas en ámbitos científicos y algunas publicaciones como también, principalmente, por las reflexiones que emergían de las aulas sinodales. Entre las decisiones de mayor peso se encuentra, precisamente, aquella de dar al Obispo diocesano una mayor potestad en el ámbito de la potestad judicial.

Pero más allá del estupor y de la sorpresa, una tal norma venía simplemente a colocar en el lugar que le corresponde la función judicial del Obispo en el ejercicio de su munus episcopal, como igualmente, a dar una señal de solida certeza a los fieles encomendados a su cuidado.

En el directorio para el ministerio pastoral de los Obispos Apostolorum succesores (2004), se lee: «El ejercicio de la autoridad pastoral exige al Obispo la constante búsqueda de un sano equilibrio de todos los componentes de su personalidad y un sentido realista para saber discernir y decidir serena y libremente, teniendo presente sólo el bien común y el bien de las personas» ${ }^{1}$. En este sentido, prosigue el directorio, «El buen gobierno exige al Obispo que busque personalmente con todas sus fuerzas la verdad y que se comprometa a perfeccionar su enseñanza y a cuidar no tanto la cantidad sino, más bien, la calidad de sus pronunciamientos» ${ }^{2}$, evitando así la adopción de soluciones pastorales que no respondan a la esencia y a la realidad de los problemas. «La pastoral será auténtica», concluye, «en la medida que se apoye en la verdad» ${ }^{3}$.

Por cierto, una de las dificultades mayores será la formación en materias jurídicas que no siempre son dominadas por quienes son llamados al episcopado y que deberán adquirir a lo largo del mismo ejercicio ministerial, cosa que no es siempre fácil. No olvidemos, sin embargo, que el Obispo tiene el deber de $\ll . .$. gobernar la Iglesia particular que le está encomendada con potestad legislativa, ejecutiva y judicial, a tenor del derecho» ${ }^{4}$, por lo mismo está llamado a ser un activo protagonista y no sólo un árbitro de estas materias en la curia diocesana. El Obispo diocesano, afirma Massimo del Pozzo, no es el

${ }^{1}$ Congregación para los Obispos, Directorio Apostolorum succesores, 22 feb. 2004, n. 50.

2 IDEM, n. 57.

3 IDEM.

${ }^{4}$ CIC, can. $391 \S 1$; cfr. CIC-17, can. $335 \$ 1:$ «Compete a los Obispos el derecho y el deber de gobernar la diócesis, así en las cosas espirituales como en las temporales, con potestad legislativa, judicial y coactiva, que han de ejercer en conformidad con los sagrados cánones». 
simple garante o notario de la correcta acción de sus colaboradores, sino que asume la responsabilidad directa y personal del acertamiento judicial ${ }^{5}$.

Por otra parte, entre las mismas condiciones requeridas a quienes serán promovidos al episcopado, se puede apreciar la necesidad de una adecuada integridad humana y cristiana (firmeza de fe, buenas costumbres, piedad, prudencia, buena fama, entre otras), como también condiciones objetivas cuales la edad y el tiempo de ordenación, y, no menos importante, la necesidad de una formación doctrinal sólida en vistas de la misión que se les confiere.

Si se confronta la legislación del 1917 y la del 1983, por cuanto se refiere a la formación doctrinal, es posible observar una clara concordancia entre ambas.

CIC-1917, can. 331 \& 1: Para que uno sea idóneo [al episcopado] hace falta que reúna las siguientes cualidades:

$5^{\circ}$ : Que se haya doctorado o por lo menos licenciado en sagrada Teología o en Derecho canónico en algún ateneo o instituto de estudios aprobado por la Santa sede, o que al menos este bien impuesto en dichas materias; $y$, si es religioso, que haya recibido de sus Superiores mayores un título equivalente o el atestado de verdadera competencia.
$C I C$, can. $378 \S 1$ : Para la idoneidad de los candidatos al Episcopado se requiere que el interesado sea:

$5^{\circ}$ : doctor o al menos licenciado en Sagrada Escritura, teología o derecho canónico, por un instituto de estudios superiores aprobado por la Sede Apostólica, o al menos verdaderamente experto en esas disciplinas.

Si bien por una parte se privilegian los títulos académicos conseguidos en centros de estudios aprobados por la Santa Sede (ser doctor o licenciado en Teología o Derecho canónico en el Código del 1917; también en Sagrada Escritura en el Código del 1983), en ausencia de ellos se requiere que el candidato «esté bien impuesto en dichas materias» o que sea «verdaderamente experto en estas disciplinas». Ello en correspondencia con la misma naturaleza de la función ministerial llamada a cumplir en el seno de la Iglesia particular.

${ }^{5}$ Cfr. M. DEL Pozzo, Il processo matrimoniale più breve davanti al Vescovo, Roma 2016, 196. 
El Obispo no está llamado a conducir la porción del pueblo de Dios que le ha sido encomendada sólo con tanta buena voluntad y con la ayuda del Espíritu Santo, necesaria, por cierto, sino también con la ciencia necesaria para poder responder con la requerida autoridad a las necesidades de este pueblo del cual son Pastores, Maestros y Jueces.

Decía San Juan Pablo II a la Rota Romana, en un texto que podríamos definir de clásico e incluso profético:

«En los discursos anuales a la Rota romana, he recordado muchas veces la relación esencial que el proceso guarda con la búsqueda de la verdad objetiva. Eso deben tenerlo presente ante todo los obispos, que por derecho divino son los jueces de sus comunidades que por derecho divino son los jueces de sus comunidades. En su nombre administran la justicia los tribunales. Por tanto, los obispos están llamados a comprometerse personalmente para garantizar la idoneidad de los miembros de los tribunales, tanto diocesano como interdiocesanos, de los cuales son moderadores, y para verificar la conformidad de las sentencias con la doctrina recta».

«Los pastores sagrados no pueden pensar que el proceder de sus tribunales es una cuestión meramente "técnica", de la que pueden desinteresarse, encomendándola enteramente a sus jueces vicarios» ${ }^{6}$.

El Obispo diocesano, por tanto, no debe considerarse ajeno o externo al proceder del tribunal. Él es «juez natural» para los fieles en su diócesis en virtud de la misma ordenación episcopal y la misión canónica recibida. Por ello mismo, ser «moderadores» no es igual a ser simples «vigilantes» 0 «controladores» de la acción judicial de los Tribunales. Los Obispos, tanto en la legislación precedente como en la normativa vigente, especialmente ahora con la introducción del proceso breve, son actores en primera línea.

El Obispo debe proveer a su formación personal y, al mismo tiempo, promover la formación de quienes serán nominados al servicio en los Tribunales, garantizarles los medios necesarios, vigilar sobre la recta administración de la justicia, evitando que se generen abusos, administrando en algunos casos por sí mismo la justicia. En resumidas cuentas, el Obispo es el primer responsable de la administración de la justicia en su diócesis.

${ }^{6}$ JUAn PABLo PP. II, Discurso a la Rota Romana, 29 enero 2005, n. 4, en http://w2.vatican.va/content/john-paul-ii/es/speeches/2005/january/documents/hf_jp-ii_spe_20050129_romanrota.html. 


\section{LA RECIENTE NORMATIVA, ¿ES NOVEDAD O REDESCUBRIMIENTO?}

Desde mi punto de vista, la potestad judicial del Obispo evidenciada en el motu proprio Mitis Iudex Dominus Iesus, promulgado el 15 de agosto del 2015, no representa absolutamente una novedad, en cuanto el can. $1419 \$ 1$ del Código vigente ya establece que el Obispo diocesano es, por oficio, juez de primera instancia con la capacidad de actuar por sí mismo o bien mediante otros; así también lo establecía el precedente can. 1572 del Código Pío benedictino con pocas diferencias ${ }^{7}$. El can. $1673 \$ 1$ introducido por el motu proprio y sin abolir el can. $1419 \$ 1$ del Código, aplica este criterio al proceso matrimonial canónico.

Can. $1419 \$ 1$. En cada diócesis, y para todas las causas no exceptuadas expresamente por el derecho, el juez de primera instancia es el Obispo diocesano, que puede ejercer la potestad judicial por sí mismo o por medio de otros de acuerdo a los cánones que siguen.
Can. $1673 \$ 1$. En cada diócesis $\boldsymbol{e l}$ juez de primera instancia para las causas de nulidad del matrimonio, para las cuales el derecho no haga expresamente excepción, es el Obispo diocesano, que puede ejercer la potestad judicial por sí mismo o por medio de otros, conforme al derecho ${ }^{8}$.

Ahora bien, que el obispo diocesano tenga potestad judicial con la capacidad de ejercerla por sí mismo como también por otros, sin por ello entrar en conflicto con su ministerio pastoral, había sido ya considerado en el can. 391 de la actual legislación canónica ${ }^{9}$, en el ámbito de las competencias del Obispo diocesano ${ }^{10}$.

De consecuencia, el Obispo diocesano no puede eximirse de la responsabilidad que le compete en la recta administración de la justicia en su diócesis.

${ }^{7}$ Cfr. CIC-1917, can. 1572: $\$ 1 . \ll \mathrm{El}$ juez de primera instancia en cada diócesis y para todas las causas expresamente no exceptuadas por el derecho es el Ordinario local, quien puede ejercer la potestad judicial por sí mismo o por medio de otros...».

${ }^{8}$ Francisco PP., M. Pr. Mitis et misericors Iesus, can. $1359 \$ 1$ : «En cada eparquía, el juez en el primo grado del proceso para las causas de nulidad del matrimonio, para las cuales el derecho no haga expresamente excepción, es el Obispo eparquial, que puede ejercitar la potestad judicial personalmente o por medio de otros, a norma de derecho».

9 Cfr. CIC, can. 391: $\$ 1$. «Corresponde al Obispo diocesano gobernar la iglesia particular que le está encomendada con potestad legislativa, ejecutiva y judicial, a tenor del derecho». $\$ 2$. «El Obispo ejerce personalmente la potestad legislativa; la ejecutiva la ejerce por sí o por medio de los Vicarios generales o episcopales, conforme a la norma del derecho; la judicial, tanto personalmente como por medio del Vicario judicial y de los jueces, conforme a la norma del derecho».

${ }^{10}$ Cfr. CIC, cann. 381-402. 
Así lo afirma la Constitución dogmática Lumen Gentium: «Los Obispos rigen como vicarios y legados de Cristo las Iglesias particulares que se les han encomendado, con sus consejos, con sus exhortaciones, con sus ejemplos, pero también con su autoridad y con su potestad sagrada que ejercitan únicamente para edificar su grey en la verdad y la santidad, teniendo en cuenta que el que es mayor ha de hacerse como el menor y el que ocupa el primer puesto, como el servidor (cfr. Lc 22,26-27)». El documento conciliar, luego de sostener que esta potestad es propia, ordinaria e inmediata, si bien circunscrita en precisos límites, agrega: «En virtud de esta potestad, los Obispos tienen el sagrado derecho y ante Dios el deber de legislar sobre sus súbditos, de juzgarlos y de regular todo cuanto pertenece al culto y organización del apostolado» ${ }^{11}$.

Que el motu proprio recuerde el rol de «Juez de primera instancia» del Obispo quiere evidenciar, por otra parte, el rostro colegial de la administración de la justicia en la Iglesia, incluso en materias complejas y delicadas como las declaraciones de nulidad matrimonial. En estos casos, el Obispo no es sólo garante, sino que también responsable de frente a Dios, de frente a la Iglesia y de frente a los mismos fieles que piden una respuesta de justicia y de verdad sobre el propio vinculo conyugal, sea que se trate de la validez o de la nulidad del mismo, una respuesta que les done certeza y serenidad para enfrentar la vida en la Iglesia $^{12}$, con un acompañamiento que sea pastoralmente adecuado a cada situación.

Es justamente el interés por la verdad y por el bien de los fieles que se encuentran bajo su cura pastoral la hace necesario recuperar una potestad ya inherente al ministerio episcopal, potestad que hoy se presenta como una «novedad» y que pone en evidencia la responsabilidad personal de cada Obispo en comunión profunda con la suprema autoridad de la Iglesia ${ }^{13}$.

${ }^{11}$ Cfr. $L G$, n. 27.

12 Sostiene F. Heredia Esteban (El proceso más breve ante el Obispo, Anuario de derecho canónico 5, Supl. [octubre 2016] 97-122, 121): «El Papa redescubre, en cierto modo, el ministerio judicial del Obispo y lo pone en relación inmediata con el gran número de fieles que, habiendo sufrido un fracaso matrimonial y dudando de la validez del vínculo contraído, necesitan una respuesta de verdad judicial que consuele sus conciencias y los ayude a vivir con mayor plenitud su pertenencia a la comunidad eclesial. En definitiva, hace desaparecer cualquier prejuicio que viera en la administración de la justicia un enemigo de la actividad pastoral o apostólica de la Iglesia misma».

13 Tribunal Apostólico de la Rota Romana, Subsidio aplicativo del Motu proprio Mitis Iudex Dominus Iesus, Ciudad del Vaticano 2016, Introducción: «Se intersectan en la nueva normativa, por lo mismo, la responsabilidad de cada Obispo y la suprema autoridad del sucesor de Pedro, cabeza del Colegio episcopal, que no puede existir sin él. Papa Francisco pide a los Pastores de las iglesias locales de ejercitar y vivir su potestad sacramental de padres, maestros y jueces y los llama a desempeñar el ministerio del servicio por la salvación de los fieles que le han sido enco- 
Por otra parte, como se puede deducir de cuanto hemos dicho hasta el momento, el rol activo del Obispo en el ámbito procesal, junto a responder a las funciones que le han sido encomendadas en la consagración episcopal (ser pastor, maestro y juez) y en la respectiva misión canónica, representa también una mayor proximidad de las estructuras eclesiales a los fieles ${ }^{14}$, especialmente aquellos servicios que se prestan a la familia y, de particular modo, los tribunales eclesiásticos. De hecho, el mismo Decano del Tribunal Apostólico de la Rota Romana afirmaba que la primera grande novedad que emerge de los motu proprio, es «que los Obispos vuelvan a asumir el ejercicio de los santos Obispos de los primeros siglos de la Iglesia, que manifestaban personalmente la potestad sacramental -recibida con la imposición de las manos en la ordenación episcopal- de padres, maestros y jueces» ${ }^{15}$.

En esta línea, me parece bastante luminosa la expresión del Papa Francisco cuando introduce el motu proprio dirigido a las Iglesias orientales: «En esta perspectiva, es importantísimo e ministerio del Obispo, quien, según la enseñanza de los Padres orientales, es juez y médico, porque el hombre, herido y caído (peptoküs) a causa del pecado original y de los propios pecados personales, enfermo, con las medicinas de la penitencia obtiene de Dios la sanación y el perdón y es reconciliado con la Iglesia» ${ }^{16}$. El Pontífice agrega inmediatamente una segunda idea, dando mayor solidez a la precedente: «El Obispo -constituido por el Espíritu Santo como figura de Cristo y al puesto de Cristo ("eis typon kai tòpon Christou")- es sobretodo ministro de la divina misericordia; por tanto, el ejercicio de la potestad judicial es el lugar privilegiado en el cual, mediante la aplicación de los principios de la "oikonomia" y de la "akribeia", él lleva a los fieles necesitados la misericordia sanadora del Señor» ${ }^{17}$.

La actuación judicial del Obispo en primera persona y no sólo delegando esta potestad, por una parte favorece la cercanía al pueblo que le ha sido

mendados, haciéndose disponibles a la escucha, en tiempos y modos que subrayan el valor de la misericordia y de la justicia».

${ }^{14}$ Decía Mons. P. V. Pinto en una entrevista: «Como ya lo había dispuesto Pío X a inicios del siglo XX, el Pontífice quiso restituir plenamente el ejercicio de la potestad judicial al obispo diocesano y al arzobispo metropolitano, es decir al arzobispo de una provincia eclesiástica. De este modo el Papa Francisco quiere alcanzar una mayor cercanía de las estructuras de la Iglesia a los fieles» (P. V. PINTO, Decano de la Rota Romana, Entrevista Esperanza sin miedos, en L'Osservatore Romano, 9 de octubre 2015).

15 P. V. PINTO, La riforma del processo matrimoniale per la dichiarazione di nullità, en L'Osservatore Romano, 8 de septiembre 2015.

${ }^{16}$ Francisco PP, M. Pr. Mitis et misericors Iesus, Introducción.

17 IDEM. 
encomendado y, por otra, da garantías de justicia y de verdad al mismo proceso judicial, fortaleciendo la estructura del Tribunal y a sus mismos operadores.

Es evidente que con esta nueva normativa se supera el límite de prudencia establecido por la Instrucción Dignitas Connubii en el art. $22 \$ 2$ que, luego de haber recordado al primer parágrafo la potestad judicial del Obispo para las causas matrimoniales, establecía un criterio de oportunidad: «Sin embargo, conviene que [el Obispo] no juzgue por sí mismo a no ser que lo exijan causas especiales» ${ }^{18}$.

A la luz de la nueva normativa, y en manera particular de las causas tratadas con el proceso breve, la requerida presencia del «Obispo juez» ofrece una mayor garantía de certeza, evitando que, con la pretendida celeridad del proceso, se ponga en riesgo la indisolubilidad del matrimonio. Dicho sea de paso que en los presupuestos que guiaron al Papa Francisco en la constitución de la comisión pontificia para la revisión del proceso matrimonial canónico, uno de los principios fundamentales, junto al de conservar la estructura de un «proceso judicial» y no administrativo, como algunos Padres sinodales habían sugerido, se encontraba también el de salvar el principio de la indisolubilidad del matrimonio, evitando en este modo que la celeridad de los procesos provocase un aumento descontrolado e irracional de las nulidades matrimoniales ${ }^{19}$.

Como sugiere Paolo Moneta, esta exigencia de celeridad puede en efecto poner en riesgo el principio de la indisolubilidad del matrimonio. De aquí la necesidad de encomendar los juicios más delicados al mismo Obispo que, en fuerza de su oficio pastoral, es con Pedro el mayor garante de la unidad católica en la fe y en la disciplina ${ }^{20}$. El mismo Pontífice reconoce el riesgo cuando, al cuarto criterio afirma, sin medios términos: «No se me escapa, sin embargo, cuánto un juicio abreviado pueda poner en riesgo el principio de la indisolubilidad del matrimonio; precisamente por esto he querido que en tal proceso sea constituido juez el mismo Obispo, que en virtud de su oficio pastoral es con Pedro el mayor garante de la unidad católica en la fe y la disciplina ${ }^{21}$. La presencia del Obispo juez quiere, por tanto, evitar el peligro de caer en algún tipo de laxismo, asegurando una mayor cercanía de los órganos judi-

${ }^{18}$ Cfr. Pont. Consiglio Per l'Interpretazione dei Testi Legislativi, Istr. Dignitas connubii, art. $22 \$ 2$.

19 Cfr. Francisco PP, M. Pr. Mitis et misericors Iesus, Introducción.

20 P. Moneta, La dinamica processuale nel m.p. «Mitis Iudex», Seminario di studio presso la Lumsa, Roma 30 ottobre 2015, en http://consotiatio.org/repository/Moneta_Lumsa.pdf, p. 2.

${ }^{21}$ Francisco PP, M. Pr. Mitis Iudex Dominis Iesus, Criterios fundamentales, IV; cfr. Introducción. 
ciales a los fieles, evidenciando que, al ser pastor y cabeza de su Iglesia, el Obispo es por ello mismo juez entre sus fieles ${ }^{22}$.

Ahora bien, si el proceso breve exige que el Obispo intervenga como juez, en el proceso ordinario no hay mayores variaciones a cuanto hasta ahora se realiza, ya que el Obispo, si bien es juez natural, puede delegar a otros esta función. Se lee en el tercer criterio que introduce la normativa del motu proprio: «En orden a que sea traducida en práctica la enseñanza del Concilio Vaticano II en un ámbito de gran importancia, se ha establecido hacer evidente que el mismo Obispo en su Iglesia, de la que es constituido pastor y cabeza, es por eso mismo juez entre los fieles que se le han confiado. Se espera por tanto que, tanto en las grandes como en las pequeñas diócesis, el Obispo mismo ofrezca un signo de la conversión de las estructuras eclesiásticas, y no deje la función judicial en materia matrimonial completamente delegada a los oficios de la curia», en sintonía con el can. 1419 y, con cuanto contenido en el Directorio Apostolorum successores, sobre el ministerio de los Obispos, al $\mathrm{n}^{\circ}$ $158^{23}$. El mismo tercer criterio pone en relieve la obligatoriedad del Obispo juez en el proceso breve: «Esto valga especialmente en el proceso más breve, que es establecido para resolver los casos de nulidad más evidente» ${ }^{24}$.

Considero útil recordar en este punto algunos criterios contenidos en el mencionado directorio sobre la función del Obispo como juez.

El directorio, luego de haber recordado la «sabia equidad canónica» con la cual el Obispo es llamado a juzgar en vistas del bien de las personas y de la misma Iglesia ${ }^{25}$, establece algunos criterios para el ejercicio de su función judicial, entre ellos: actuar en modo que los fieles resuelvan pacíficamente sus controversias; promover la reconciliación entre ellos; observar las normas procedurales establecidas para el ejercicio de la potestad judicial; investigar con

${ }^{22}$ Cfr. P. Moneta, La dinamica processuale nel m.p. «Mitis Iudex», 2.

23 «... el Obispo es el buen pastor que conoce a sus ovejas y es conocido por ellas, verdadero padre que se distingue por su espíritu de caridad y de celo hacia todos; sin embargo, también como juez que administra la justicia habitualmente a través del Vicario Judicial y el tribunal, él presta a la comunidad un servicio no menos excelente, imprescindible para el bien espiritual de los fieles» (Apostolorum succesores, n. 158).

${ }^{24}$ Francisco PP, M. Pr. Mitis Iudex Dominis Iesus, Criterios fundamentales, III; cfr. Introducción.

${ }^{25}$ Cfr. Apostolorum succesores, n. 65: «Como juez prudente, el Obispo juzgará según la sabia equidad canónica que es intrínseca a todo el ordenamiento de la Iglesia, teniendo delante de sus ojos a la persona, que en cada circunstancia ha de ser ayudada para alcanzar su bien sobrenatural, y el bien común de la Iglesia; por esto, con ánimo misericordioso y benigno, pero también firme, estará siempre sobre los intereses personales y, ajeno a cualquier precipitación o espíritu de parte, tratará de escuchar a los interesados antes de juzgar sus conductas». 
discreción a norma del can. 1717; vigilar sobre el actuar de su tribunal según los criterios establecidos para la administración de la justicia en la Iglesia ${ }^{26}$.

En conclusión, a cuanto hemos expuesto, se puede afirmar que la gran novedad de la norma que nos interesa es solamente la necesidad que en el proceso breve sea el Obispo, y sólo él, quien ejercite la potestad judicial, mientras que en el proceso ordinario el ejercicio de esta facultad es explícitamente facultativa $^{27}$. Del resto, la normativa a disposición es clara cuando no niega que esta función le pertenece de derecho.

${ }^{26}$ IDEM, n. 68: «Criterios del ejercicio de la función judicial. Al ejercitar la función judicial, el Obispo podrá valerse de los siguientes criterios generales:

a) Siempre que no comporte perjuicio a la justicia, el Obispo debe actuar de modo que los fieles resuelvan de manera pacífica sus controversias y se reconcilien cuanto antes, incluso cuando el proceso canónico hubiera ya comenzado, evitando así las permanentes animosidades que las causas judiciales suelen producir.

b) El Obispo observe y haga observar las normas de procedimiento establecidas para el ejercicio de la potestad judicial, pues bien sabe que tales reglas, lejos de ser un obstáculo meramente formal, son un medio necesario para verificar los hechos y obtener justicia.

c) Si tiene noticias de comportamientos que dañen gravemente el bien común eclesial, el Obispo debe investigar con discreción, solo o por medio de un delegado, los hechos y la responsabilidad de sus autores. Cuando considere que ha recogido pruebas suficientes de los hechos que han dado origen al escándalo, proceda a reprender o amonestar formalmente al interesado. Pero donde esto no bastase para reparar el escándalo, restablecer la justicia y conseguir la enmienda de la persona, el Obispo dé inicio al respectivo procedimiento para la imposición de penas, lo que podrá hacer de dos modos:

- mediante un proceso penal regular, en el caso que, por la gravedad de la pena, la ley canónica lo exija o el Obispo lo considere más prudente;

- mediante un decreto extrajudicial, conforme al procedimiento establecido en la ley canónica.

d) el Obispo, consciente del hecho que el tribunal de la diócesis ejercita su misma potestad judicial, vigilará a fin de que la acción de su tribunal se desarrolle según los principios de la administración de la justicia en la Iglesia. En particular, teniendo en cuenta la singular importancia y relevancia pastoral de las sentencias que se refieren a la validez o nulidad del matrimonio, dedicará una especial atención a tal sector, en sintonía con las indicaciones de la Santa Sede, y ante la ocurrencia de eventuales abusos, tomará todas las medidas necesarias para que éstos cesen, especialmente aquellos que impliquen el intento de introducir una mentalidad divorcista en la Iglesia. Asumirá también la responsabilidad que le corresponda en los tribunales constituidos para varias diócesis».

${ }^{27}$ Cfr. J. LlobeL, Questioni comuni ai tre processi del M. P. «Mitis Iudex», Relazione al Seminario di studio «La riforma operata dal m.p. "Mitis Iudex"», LUMSA, Roma, 30 noviembre 2015, en http://www.consotiatio.org/repository/Llobell_Lumsa.pdf, p. 9: «El ejercicio personal y monocrático de la potestad judicial de parte del Obispo diocesano en primera instancia es necesario en el processus brevior y explícitamente facultativo en el proceso documental. Es decir, en el proceso documental el juez monocrático puede ser sea el Obispo diocesano, sea el Vicario judicial, sea un juez clérigo (cfr. MI can. 1688; RP art. 21). En realidad, el nuevo can. $1673 \$ 1$, como el can. $1419 \$ 1$, ofrecen al Obispo diocesano la posibilidad del ejercicio personal de la potestad judicial utilizando el proceso ordinario o el documental, si bien hasta la promulgación del MI dicho ejercicio tuviese una naturaleza axiológica, casi retórica, sin alguna aplicación en ámbito matrimonial, en particular en los procesos judiciales sobre delicta graviora». 


\section{ANTECEDENTES HISTÓRICOS}

No es posible, en virtud del tiempo a disposición, hacer un estudio exhaustivo de los aspectos históricos sobre la figura del Obispo juez, cosa que ha sido tratada por otros autores. Mi interés es mostrar que la función judicial de los Obispos no es una invención del motu proprio de Papa Francisco, sino que pertenece a la misma tradición de la Iglesia.

Por los santos Obispos Ambrosio y Agustín, somos testigos no sólo de la función judicial que cumplían en medio del pueblo cristiano, sino también de la dedicación y del sacrificio que ello provocaba en los santos. En el libro de las Confesiones, San Agustín afirmaba de no tener la posibilidad ni siquiera de preguntarle a San Ambrosio sobre las cosas que le interesaban:

«(...) pues me apartaban de él la multitud de quienes acudían a verlo con toda clase de asuntos y a quienes atendía con gran servicialidad. Y el poco tiempo que no estaba con las gentes lo empleaba en reparar su cuerpo con el sustento necesario o en alimentar su mente con la lectura» ${ }^{28}$.

El mismo San Agustín afirma que el ejercicio del oficio judicial era un peso no indiferente de su ministerio, tanto que se veía alejar de la meditación y de la oración:

«Nosotros no nos cansamos de decir, no sólo a quien se apropia de los demás sino también a quien exige con avidez exagerada la restitución del propio, que tienen que cuidarse de toda suerte de codicia, y les presentamos la imagen de aquel hombre a quien fue dicho: Estúpido, esta noche tu alma te será quitada, y cuanto has preparado ¿de quién será? Pero no hay caso, ni siquiera si decimos esto ellos se alejan y nos dejan en paz, al contrario, nos oprimen con su abandono. Imploramos y clamamos hasta que no nos han obligado a ocuparnos de las cosas que les preocupan, alejándonos de la meditación de los mandamientos de Dios que son nuestro amor. Oh, con cuanta aversión por las turbas turbulentas y con cuanto deseo por la palabra divina fue dicho: Aléjense de mí, o malignos, y meditare los mandamientos de mi Dios» ${ }^{29}$.

De igual modo, Posidio da un importante testimonio de la preocupación que tenía San Agustín no sólo en ejercitar el servicio pastoral, sino también en

28 San Agustín, Confesiones, Libro VI, Capítulo 3.

29 San Agustín, Enarratione in Psalmos 118.24.3, en www.agustin.it/spagnolo/esposizioni_salmi/ index $2 . \mathrm{htm}$. 
resolver las controversias y administrar la justicia, quedando a veces en ayunas, mirando el bien de los cristianos, si bien soportando todo como una pesada carga que lo alejaban de platicar de las cosas de Dios con los hermanos:

«Cuando San Agustín era requerido por los cristianos o personas de otras sectas, oía con diligencia la causa, sin perder de vista lo que decía alguien; conviene a saber: que más quería resolver los pleitos de desconocidos que de amigos, pues entre los primeros es más fácil un arbitraje de justicia y la ganancia de algún amigo nuevo; en cambio, en el juicio de amigos se perdía ciertamente el que recibía el fallo contrario. A veces, hasta la hora de comer duraba la audiencia; otra se pasaba el día en ayunas, oyendo y resolviendo cuestiones. Y siempre miraba en todo al estado espiritual de los cristianos, interesándose de su aprovechamiento o defección en la fe y buenas costumbres; y, según la oportunidad, instruía a los contendientes en la ley de Dios, inculcando su cumplimiento y dándoles consejos de la vida eterna, sin buscar en los favorecidos más que la devoción y la obediencia cristiana, debidas a Dios y a los hombres. (...). Se comunicaba por cartas con algunos que le consultaban sobre asuntos temporales. Pero soportaba como una pesada carga esta distracción de más altos pensamientos, y era su mayor gusto platicar de las cosas de Dios en íntima familiaridad con los hermanos» ${ }^{30}$.

Estos testimonios permiten ver que la administración de la justicia en manera directa y personal, con el peso que significaba, no era algo circunstancial o episódico en el ministerio de los Padres, sino una realidad bastante cuotidiana a la cual no se sustraían, dedicándole bastante tiempo. Por otra parte, los pronunciamientos tenían para los cristianos un profundo valor civil y moral justamente por la autoridad de la fuente; no debemos olvidar el influjo que tuvo San Ambrosio en la diócesis de Milán, las dificultades con los emperadores Valeriano II y Teodosio, sin contar los conflictos con los arrianos ${ }^{31}$.

${ }^{30}$ Posidio, Vita de San Agustín, en http://www.augustinus.it/spagnolo/vita/possidio.htm. Afirma Massimo del Pozzo, vinculando las dificultades de San Agustín en su ejercicio judicial a la introducción del proceso breve: «La gravedad y la onerosidad del oficio judicial han sido motivo de pena y sufrimiento para los anhelitos pastorales y doctrinales de San Agustín. La experiencia y los desahogos del Doctor gratiae son una elocuente demostración de los "recursos históricos" y un estímulo a no considerar el proceso más breve como un peso al gobierno. El contacto directo con las situaciones de crisis y con las personas heridas puede ser al contrario fuente de maduración de la fe y de humanización del ministerio» (Il processo matrimoniale più breve davanti al Vescovo, 44).

31 Cfr. Storia della Chiesa, H. Jedin (dir.), vol. II, Milán 1992, 94-96. 
Si bien no sea demasiado clara la naturaleza propiamente judicial de las decisiones episcopales y si tal administración se configurase como resolución arbitral o conciliadora, lo que resulta claro es que la jurisdicción de los Obispos trasciende muchas veces las causas puramente espirituales. Es más, ellos asumen esta función ya antes de la pax constantiniana, con decisiones que adquirían un incontrovertible valor ejecutivo, inclusive siendo respetado por el poder civil ${ }^{32}$.

Con el paso de los años y de los siglos, se inicia a configurar una estructura procesual con figuras más cercanas a los fieles, normalmente archidiáconos o decanos, clérigos, que administraban la justicia en algunas materias en el mismo lugar, una suerte de «jueces locales» que ofrecían la ventaja de no retardar la justicia y de actuar tempestivamente. Es en estas circunstancias que el Concilio de Trento buscará el limitar y contrastar este fenómeno de particularización de los juicios llamando a los Obispos a asumir la plenitud de sus atribuciones.

En la sesión XXIV, del 11 de noviembre del 1563, el Concilio establece con claridad la competencia de los Ordinarios locales indicando, además, el tiempo que debía durar el proceso: «Todas las causas para las cuales es competente el foro eclesiástico, aunque si se refieren a los beneficios, en primera instancia se desarrollarán sólo delante a los ordinarios locales y serán completamente conducidas a término en el tiempo máximo de dos años desde el inicio del proceso. Trascurso este tiempo, las partes, o una de ellas, podrán recurrir a los jueces superiores, naturalmente competentes ${ }^{33}$. No sólo, en la misma sesión vienen exceptuadas las causas que deben ser tratadas por la Sede Apostólica o que hayan sido reservadas por el mismo Sumo Pontífice ${ }^{34}$, estableciendo explícitamente que: «Las causas matrimoniales y criminales, por otra parte, no serán dejadas al juicio del decano, del archidiácono o de otros de grado inferior, aunque si se encuentran en visita canónica, sino que serán

32 Cfr. M. DEL Pozzo, Il processo matrimoniale più breve davanti al Vescovo, 47: «No es demasiado clara la naturaleza propiamente judicial de la decisión episcopal; parece que se tratase principalmente, en línea con el carácter pacificador de la lex cbristiana, de una resolución arbitral o conciliativa del Obispo inter fideles con incontrovertible valor ejecutivo. (...). En los primos siglos la justicia matrimonial canónica es seguramente bastante marginal (si no del todo residual), pero el esfuerzo de los Obispos es bastante extendido e intenso en el sector latu sensu judicial. El respeto del ordenamiento civil por la jurisdicción de la Iglesia en materia propiamente religiosa (y también fuera de ella), por tanto, aparece adquirido y estabilizado». Ver también p. 49.

33 Concilio de Trento, Decreto de reforma, Sesión XXIV, 11 nov. 1563, canon XX, en Conciliorum Oecumenicorum Decreta, EDB, Bologna 1991, 772.

${ }^{34}$ Cfr. IDEM. 
reservadas sólo al examen y a la jurisdicción del Obispo, aunque si entre el Obispo y el decano o el archidiácono u otros inferiores sea pendiente una controversia, en cualquier instancia, relativa al tratamiento de estas causas» ${ }^{35}$.

De cuanto dicho, es posible afirmar que la gravedad de las causas matrimoniales y criminales y su incidencia en la salus animarum, requería una singular discreción, diligencia y aplicación que la persona del Obispo era en grado de asegurar.

Como bien concluye Massimo del Pozzo, «Las disposiciones tridentinas han representado la base de la organización judicial eclesiástica hasta la modernidad. (...). El tribunal diocesano constituyó, por tanto, el prototipo de la justicia local. El Obispo recuperó la directa responsabilidad de las causas matrimoniales sobre una base territorial», si bien ello no comportaba necesariamente el ejercicio personal del juicio por parte del Obispo, en cuanto se practicaba la concesión de la potestad a jueces delegados con la asistencia de asesores y colaboradores, sin por ello eximir al Obispo de «un rol inmediato de control y supervisión de la actuación del tribunal y, no era extraño, de intervención directo» ${ }^{36}$.

En la codificación Pío benedictina, la constitución de los tribunales presupone siempre la facultad del Ordinario de ejercitar la función judicial, subordinada sin embargo a las prescripciones legales universalmente establecidas que favorecen la constitución del provisor y los vice provisores ${ }^{37}$, «sacerdotes de fama intachable, doctores o al menos peritos en derecho canónico y que no cuenten menos de treinta años de edad $»^{38}$. Aparte de ello, pueden ser nombrados algunos sacerdotes como jueces sinodales, no más de doce establece el can. $1574 \$ 1$, que sean peritos en derecho, aunque pertenezcan a otras diócesis ${ }^{39}$.

Ahora bien, el Código Pío benedictino, luego de colocar en resalto la función judicial del Obispo estableciendo que él es el juez de primera instancia en cada diócesis para todas las causas, salvo aquellas exceptuadas por el derecho ${ }^{40}$, o bien cuando se trata de derechos o bienes temporales del Obispo, de la mesa

\footnotetext{
5 IDEM.

6 M. DEL Pozzo, Il processo matrimoniale più breve davanti al Vescovo, 54.

7 Cfr. CIC-1917, can. 1573 \$\$ 2-3.

CIC-1917, can. $1573 \$ 4$.

39 Cfr. CIC-1917, can. $1574 \$ 1$.

40 CIC-1917, can. 1572 \$ 1: «El juez de primera instancia en cada diócesis y para todas las causas no exceptuadas por el derecho es el Ordinario local, quien puede ejercer la potestad judicial por sí mismo o por medio de otros, pero observando los cánones que siguen».
} 
o de la Curia diocesana ${ }^{41}$, al can. 1578 establece que «el Obispo siempre puede presidir el tribunal por sí mismo», recomendando, en todo caso, que deje las causas para que «las juzgue el tribunal ordinario presidido por el provisor o vice provisor», especialmente aquellas criminales o contenciosas de mayor gravedad $^{42}$. Del mismo modo, la instrucción Provida Mater Ecclesiae, precisará en el 1936, las prescripciones sobre la formación del tribunal colegial y la inoportunidad de la presidencia del Obispo ${ }^{43}$, confirmando, sin embargo, la exclusividad de la competencia del Ordinario a declarar la nulidad en vía documental ${ }^{44}$.

Que corresponda al Obispo, «juez natural», tratar las causas de nulidad matrimonial de la Iglesia particular, no sólo en teoría, sino que también en la práctica, es una constante, a pesar de que la evolución del sistema judicial en época moderna, se haya orientado al descentramiento orgánico de la función judicial y a un ejercicio en forma vicaria cada vez más acentuado. Dice Del Pozzo: «El processus matrimonialis brevior coram Episcopo, por tanto, es más un retorno al antiguo que una novedad. En un cierto sentido ha existido casi persistentemente una forma personal típicamente episcopal, para la declaración de nulidad matrimonial», y concluye: «Hasta el siglo XIX la potestad judicial del Obispo se manifestaba no sólo en el frecuente contacto con los ministros o en el control del tribunal diocesano, sino que en la referencia directa a su persona y capitalidad» ${ }^{45}$.

Se puede concluir esta veloz visión histórica con las palabras de San Juan Pablo II en la exhortación Pastores gregis: «... el ministerio del Obispo en modo alguno se puede reducir al de un simple moderador. Por su naturaleza, el $m u$ nus episcopale implica un claro e inequívoco derecho y deber de gobierno, que incluye también el aspecto jurisdiccional. Los Pastores son testigos públicos y su potestas testandi fidem alcanza su plenitud en la potestas iudicandi: el Obispo no

${ }^{41}$ CIC-1917, can. $1572 \$ 2:$ : Mas si se trata de derechos o bienes temporales del Obispo o de la mesa o Curia diocesana, la causa debe llevarse para su decisión, o bien, con el consentimiento del Obispo, al tribunal colegiado diocesano, que se compone del provisor y de los dos jueces sinodales más antiguos, o bien al juez inmediato superior».

42 CIC-1917, can. 1578: «Fuera de las causas que se mencionan en el can. $1572 \$ 2$, el Obispo siempre puede presidir el tribunal por sí mismo; pero es muy conveniente deje las causas, sobre todo las criminales y las contenciosas de mayor gravedad, para que las juzgue el tribunal ordinario presidido por el provisor o vice provisor».

43 Cfr. Sacra Congregación para la Disciplina de los Sacramentos, Instr. Provida Mater Ecclesiae, 15 de agosto 1936, art. $14 \$ 3$.

${ }^{44}$ Cfr. IDEM., art. $227 \$ 1 ; 228$.

${ }^{45}$ M. DEL Pozzo, Il processo matrimoniale più breve davanti al Vescovo, 56. 
sólo está llamado a testimoniar la fe, sino también a examinarla y disciplinar sus manifestaciones en los creyentes confiados a su cuidado pastoral» ${ }^{46}$.

\section{EXIGENCIAS DE LA NUEVA NORMATIVA}

En la reciente exhortación apostólica postsinodal Amoris laetitia, el Papa Francisco establece un importante criterio que da fundamento a la función judicial de Obispo y que, por otra parte, ha motivado la necesidad de emanar los motu proprio que reforman el proceso matrimonial canónico. Él afirma que junto al deseo de simplificar los procedimientos de una eventual declaración de nulidad matrimonial: «también he querido "hacer evidente que el mismo Obispo en su Iglesia, de la que es constituido pastor y cabeza, es por eso mismo juez entre los fieles que se le han confiado" ${ }{ }^{47}$.

Creo que es evidente de esta afirmación que las exigencias que recaen en los hombros de los Obispos no son de poca importancia. La presencia del Obispo juez en su Iglesia particular exige no sólo la capitalidad de su ministerio, sino también la sacramentalidad del mismo ${ }^{48}$, en cuanto el munus judicial no puede separarse de aquellos de enseñar y santificar. Por lo mismo, la reforma requiere que el Obispo no deje completamente delegada a los oficios de la curia la función judiciaria en materia matrimonial, y esto especialmente en el proceso más breve que viene establecido para resolver los casos de nulidad más evidentes ${ }^{49}$.

Quisiera recordar, antes de proseguir, que los mismos Obispos reunidos en los Sínodos para la familia del 2014 y del 2015, han solicitado la simplificación de la praxis canónica de los procesos matrimoniales.

En el Sínodo extraordinario del 2014, los Obispos piden la simplificación de la praxis canónica de las causas matrimoniales ${ }^{50}$, si bien actuando con pru-

${ }^{46}$ JuAn Pablo PP. II, Exhort. ap. postsinodal Pastores gregis: sobre el Obispo servidor del evangelio de Jesucristo para la esperanza del mundo, 16 oct. 2003, n. 44.

47 FranCISCO PP., Exhort. ap. postsinodal Amoris laetitia, n. 244.

48 Cfr. Tribunal Apostólico de la Rota Romana, Subsidio aplicativo..., Elementos principales, Ciudad del Vaticano, 2016: Pilares fundamentales de la reforma, 1. La centralidad del Obispo en el servicio de la justicia: «El Obispo en su Iglesia, como padre y juez, es icono de Cristo-Sacramento. Por lo mismo él sea personalmente juez, dando un signo de la potestad sacramental».

49 Cfr. La riforma dei processi matrimoniali di Papa Francesco. Una guida per tutti, a cura della Redazione di Quaderni di diritto ecclesiale, Milano 2016, 94.

50 SíNODO DE OBISPOS, III Asamblea general extraordinaria: Los desafíos pastorales de la familia en el contexto de la evangelización, Instrumentum laboris, Ciudad del Vaticano 2014, n. 98: «Existe una amplia solicitud de simplificación de la praxis canónica de las causas matrimoniales. Las posiciones son diferentes: algunos afirman que agilizarlas no es un remedio eficaz; otros, favorables 
dencia al fin de evitar el riesgo de provocar injusticias y errores que puedan dar la impresión de no respetar la indisolubilidad del sacramento, cuidando por un lado de no favorecer el abuso y, por otro, de no obstaculizar la formación de los jóvenes al matrimonio como compromiso para toda la vida, evitando la concepción de un «divorcio católico» ${ }^{51}$. Muchos padres en este mismo Sínodo extraordinario promueven la concesión de una mayor autoridad al Obispo en materia procesual ${ }^{52}$.

Sucesivamente, en las jornadas de estudio del Sínodo ordinario del 2015, los Obispos consideran importante subrayar la responsabilidad del Obispo diocesano en materia procesual, pudiendo indicar consultores preparados que, gratuitamente, puedan aconsejar a las partes sobre la validez del propio matrimonio $^{53}$.

En la Relación final del Sínodo ordinario, los Padres sinodales afirman que la simplificación realizada con la normativa promulgada por el Papa, «es una gran responsabilidad para los Ordinarios diocesanos, llamados a juzgar ellos mismos algunas causas y a garantizar, en todos los modos, un acceso más fácil de los fieles a la justicia» ${ }^{54}$.

Respecto a la normativa en estudio, los cánones que interesan son el can. 1683, que indica las causas de tratar directamente por el Obispo ${ }^{55}$, y

\footnotetext{
a la agilización, invitan a explicar bien la naturaleza del proceso de declaración de nulidad, para una mejor comprensión de éste de parte de los fieles».

${ }^{51}$ Cfr. IDEM, n. 99.

52 Cfr. IDEM, n. 100: «Muchos piden como elementos de esta agilización: proceso canónico simplificado y más rápido; concesión de mayor autoridad al Obispo local; mayor acceso de los laicos como jueces; reducción del costo económico del proceso. (...). Se propone, asimismo, descentralizar la tercera instancia. En todas las áreas geográficas, se pide un planteamiento más pastoral en los tribunales eclesiásticos, con una mayor atención espiritual a las personas».

53 SíNOdo DE OBISPOS, XIV Asamblea general ordinaria, La vocación y la misión de la familia en la Iglesia y en el mundo contemporáneo, Instrumentum laboris, Ciudad del Vaticano 2015, n. 116: «Sobre las causas matrimoniales, la simplificación del procedimiento, solicitado por muchos, junto a la preparación de suficientes operadores, clérigos y laicos con dedicación prioritaria, exige subrayar la responsabilidad del Obispo diocesano quien, en su diócesis, podría encargar a consultores debidamente preparados que puedan gratuitamente aconsejar a las partes sobre la validez del propio matrimonio. Tal función puede ser desarrollada por una oficina o personas cualificadas (cfr. $D C$, art. 113, 1)».

${ }^{54}$ SínODO DE OBISPOS, XIV Asamblea general ordinaria, La vocación y la misión de la familia en la Iglesia y en el mundo contemporáneo, Relación final, Ciudad del Vaticano 2015, n. 82.

55 Francisco PP, Mot. Prop. Mitis Iudex Dominus Iesus, can. 1683: «Al mismo Obispo compete juzgar las causas de nulidad cada vez que: $1^{\circ}$ la petición haya sido propuesta por ambos cónyuges o por uno de ellos, con el consentimiento del otro; $2^{\circ}$ concurran circunstancias de las personas y de los hechos, sostenidas por testimonios o documentos que no requieran una investigación o una instrucción más precisa, y hagan manifiesta la nulidad».
} 
el can. $1687 \$ 1$ que establece cuándo y cómo el Obispo puede dar sentencia y cuándo remitir el proceso al examen ordinario ${ }^{56}$. El art. 21 de las Reglas de procedimiento para tratar las causas de nulidad de matrimonio, contenidas en el mismo Motu proprio, establece además el modo en el cual el Obispo debe pronunciar la sentencia y la forma en que va presentado su contenido ${ }^{57}$.

La reforma requiere, de hecho, diversas acciones de parte del Obispo, exigencias a las cuales no puede renunciar y a las que gradualmente deberá responder en la administración de la justicia en su diócesis. En modo concreto, el Obispo diocesano deberá:

- Preparar personal suficiente para los tribunales, clérigos y laicos, mediante cursos de formación en instituciones académicas debidamente aprobadas o bien promovidos por la misma diócesis.

- Colocar a disposición de las personas separadas o de las parejas en crisis un servicio de información, de consejo y de mediación vinculado a la pastoral familiar que podrá, eventualmente, acoger a las personas en vista de la investigación preliminar del proceso.

- Tener un propio Tribunal en sus diócesis para las causas matrimoniales, pudiendo todavía de servirse de un Tribunal interdiocesano.

- El Obispo diocesano es llamado a ser Juez de primera instancia para las causas de nulidad matrimonial, con la capacidad de actuar por sí mismo o por medio de otros, dando así mayores garantías al proceso, delante de Dios, la Iglesia y los fieles; este rol judicial del Obispo es inherente a su consagración episcopal, facultativo en el proceso ordinario, obligatorio en el proceso breve.

Como afirma el Subsidio aplicativo, luego de haber sostenido que el Obispo es juez en su Iglesia, establece: «Ello vale especialmente en el proceso breve: no es el Obispo que instruye la causa, interrogando las partes y los testigos, pero él interviene como juez en los casos en que la nulidad es evidente. La verdad de juicio viene salvada, ya que personas cualificadas asisten al Obis-

${ }^{56}$ IDEM, can. $1687 \$ 1:$ :Recibidas las actas, el Obispo diocesano, consultando al instructor y al asesor, examinadas las observaciones del defensor del vínculo y, si existen, las defesas de las partes, si alcanza la certeza moral sobre la nulidad del matrimonio, dé la sentencia. En caso contrario, remita la causa al proceso ordinario».

57 Francisco PP, Mot. Prop. Mitis Iudex Dominus Iesus, Reglas de procedimiento para tratar las causas de nulidad de matrimonio, art. 21: $\ll$ 1. El Obispo diocesano establezca, según su prudencia, el modo con el que pronunciar la sentencia. $\$ 2$. La sentencia, siempre firmada por el Obispo junto con el notario, exponga en manera breve y ordenada los motivos de la decisión y ordinariamente sea notificada a las partes dentro del plazo de un mes desde el día de la decisión». 
po, quien asume luego la certeza moral sobre la sentencia de pronunciar» ${ }^{58}$. De cuanto dicho en el Subsidio, es importante subrayar que el Obispo debe llegar al convencimiento, en base a su ciencia y consciencia, que las pruebas y los indicios producidos demuestran la invalidez del matrimonio. Si el Obispo no logra tal certeza moral, es decir, si no está seguro de la nulidad del matrimonio, no tendrá otra alternativa que enviar la causa al trámite ordinario que examinará más profundamente la cuestión, permitiendo en este modo que las partes accedan a un acertamiento de la verdad que se refiere a la validez o invalidez de su matrimonio según el proceso ordinario ${ }^{59}$.

La naturaleza eminentemente pastoral de la función judicial del Obispo en el proceso breve, es avalorada con el hecho que él no tiene la facultad de concluir la causa con una sentencia negativa ${ }^{60}$.

\section{Problemáticas y desafíos}

De cuanto hemos dicho hasta el momento, diversas son las inquietudes que dejaremos abiertas al final de nuestra relación. Inquietudes que, como se comprenderá en seguida, son también desafíos que deberán ser asumidos en el curso del tiempo y que adquirirán fisonomías diversas de acuerdo al lugar y a la situación en que se encuentran los mismos tribunales.

Se preguntaba Mons. Pío Vito Pinto, el Decano de la Rota Romana, en concomitancia con la publicación de la nueva normativa: «Pero, ¿cómo podrán los Obispos diocesanos, o los Obispos eparquiales, sobre todo en las grandes diócesis, asegurar, al menos en parte y como signo, esta tarea de pastores jueces? ${ }^{61}$. La respuesta para Pinto no es otra que la formación, sea aqué-

58 Tribunal Apostólico de la Rota Romana, Subsidio aplicativo..., Elementos principales, Ciudad del Vaticano 2016.

59 Cfr. L. SABBARESE, Il processo più breve: condizione per la sua introduzione, procedura, decisione, en Tra rinnovamento e continuità. Le riforme introdotte dal motu proprio Mitis Iudex Dominus Iesus, Roma 2016, 56.

${ }^{60}$ P. Moneta (La dinamica processuale nel m.p. «Mitis Iudex», 18-19), afirma: «Si considera de no poder adquirir aquella certeza moral requerida para declarar nulo el matrimonio, él deberá dejar a las partes en condición de obtener un estudio más profundo de su causa, en modo que no quede en ellos la sensación de que la Iglesia no haya adecuadamente considerado su exigencia de clarificar la situación personal en la cual se encuentran. El Obispo transmitirá, por tanto, la causa al Vicario judicial competente (es decir aquel que había iniciado el tratamiento de la causa, incardinándola en el proceso breve), para que proceda según la disciplina procesual del proceso ordinario».

${ }^{61}$ P. V. PINTO, Decano de la Rota Romana, La riforma del processo matrimoniale... 
lla dirigida a formar personas que sirven en los Tribunales, sea la formación permanente de los mismos Obispos. Prosigue el Decano: «La formación permanente ayudará a que cada Obispo, teniendo el propio tribunal para las causas matrimoniales, redescubra el ministerio, que le ha sido encomendado en la ordenación, de ser juez de sus fieles» ${ }^{62}$.

Si bien se pida bastante a los Obispos, es necesario recordar que ésta fue la dirección que el Sínodo y el mismo Papa han dado a la Iglesia. No sólo, es la realidad misma que ha vivido la Iglesia desde sus orígenes. De allí que sea necesario un cambio estructural y, al mismo tiempo, un cambio personal que favorezca la recuperación de la centralidad del Obispo diocesano en la praxis judicial. Por otra parte, la autoridad llamada a participar en el proceso breve es el «Obispo diocesano» ${ }^{63}$, como lo establece el motu proprio, por lo que serían de excluir tanto la presencia del Obispo auxiliar que del Obispo coadjutor.

Se puede afirmar, por tanto, que como ya hemos dicho, la tarea judicial del Obispo no es algo residual o marginal en su ministerio; ella es inherente a la misma misión pastoral recibida en la consagración episcopal. De allí la necesidad de una formación que venga en ayuda a los Obispos para asumir las exigencias de la presente normativa. El hecho que un Obispo carezca de una formación jurídica conseguida en un centro académico para ello habilitado, requerirá de la ayuda de colaboradores expertos y técnicamente formados que, sin embargo, no lo sustituirán completamente en sus funciones ${ }^{64}$.

En virtud de cuanto establecido en el art. $8 \$ 1$ de las Reglas de procedimiento ${ }^{65}$, el Obispo que no tienen un tribunal propio, deberá proveer a formar adecuadamente personas que puedan prestar su trabajo para las causas de nulidad en el tribunal. Si bien el articulo habla de «cursos de formación permanente y continua», sea promovidos por las mismas diócesis que por la Sede Apostólica, creo que es necesario tener presente cuáles deben ser los criterios formativos. Si de una parte se promoverán -y ya se está haciendo- cursos rápidos para el personal que trabaja en los tribunales, estoy convencido que no

62 IDEM.

63 Cfr. Francisco PP, Mot. Prop. Mitis Iudex Dominus Iesus, can. $1687 \$ 1$.

64 Cfr. M. DEL Pozzo, Il processo matrimoniale più breve davanti al Vescovo, 83.

65 Francisco PP, Mot. Prop. Mitis Iudex Dominus Iesus, Reglas de procedimiento para tratar las causas de nulidad de matrimonio, art. $8 \$ 1$ : «En las diócesis que no tienen un tribunal propio, el Obispo debe preocuparse de formar cuanto antes, mediante cursos de formación permanente y continua, promovidos por las diócesis o sus agrupaciones y por la Sede Apostólica en comunión de objetivos, personas que puedan prestar su trabajo en el tribunal que ha de constituirse para las causas de nulidad». 
se debe descuidar la calidad de los mismos, por lo cual es necesario que las mismas diócesis provean a la formación cualificada de algunos fieles, laicos y clérigos, en los centros de estudio de derecho canónico con la obtención de un correspondiente título académico. Junto a ello, será necesario revisar los programas formativos de Licencia y Doctorado para venir al encuentro de las necesidades de las mismas diócesis, especialmente aquellas más necesitadas.

Otro problema que debe ser considerado, es la tendencia al «buenismo» o la condescendencia injustificada de parte de los Pastores. La administración de la justicia, especialmente en el contexto del proceso breve, requiere que el Pastor no se deje llevar por la tendencia de dar una solución rápida a las partes que recurren al tribunal sin ser objetivo en la evaluación de las pruebas, no administrando de este modo una verdadera justicia ${ }^{66}$. De aquí la importancia de la seriedad del trabajo desarrollado por el instructor y la competente asistencia del asesor, con quienes el Obispo procederá a la dedicada evaluación de las actas, la defensa del vínculo y las eventuales defensa de las partes ${ }^{67}$. Ello favorecerá un juicio sereno y objetivo, como también tomar la justa decisión de reenviar el estudio de la causa en caso de no haber adquirido la certeza moral.

Para evitar cualquier abuso en el proceso breve, el Legislador «impone como único juez al Obispo como garante y servidor fiel de la doctrina y de la unidad en comunión con el Romano Pontífice», afirma Heredia, para luego agregar que «El Obispo garantiza la aplicación correcta de la jurisprudencia evitando particularismos que tanto daño harían al bien público eclesial y a los derechos de los fieles» ${ }^{68}$. La autoridad del Obispo es un punto de certeza y ga-

${ }^{66}$ Afirma F. Heredia Esteban (El proceso más breve ante el Obispo, 121-122): «El conocimiento recto de los principios de la doctrina y la jurisprudencia evitará aplicaciones localistas y particulares ajenas a la verdad y al principio de igualdad de todos los fieles a la hora de recibir la justicia». Y agrega: «La fidelidad a los principios inspiradores de la norma y a sus preceptos concretos permitirá evitar interpretaciones reductivas o permisivas creando sistemas cerrados en el modo de impartir la verdadera justicia».

${ }^{67}$ Cfr. Francisco PP, Mot. Prop. Mitis Iudex Dominus Iesus, can. 1687 \$ : «Recibidas las actas, el Obispo diocesano, consultando al instructor y al asesor, examinadas las observaciones del defensor del vínculo y, si existen, las defensas de las partes, si alcanza la certeza moral sobre la nulidad del matrimonio, dé la sentencia. En caso contrario, remita la causa al proceso ordinario».

${ }^{68}$ F. Heredia Esteban, El proceso más breve ante el Obispo, 104. El mismo autor sostiene, en la p. 121, que: «Es el Obispo quien debe garantizar una diligente y amorosa puesta en práctica de esta reforma tratando de evitar cualquier abuso que iría contra el fin de la reforma, el propio Papa denunciaba la posibilidad de los abusos que pueden producirse, de ahí la necesidad de formar clérigos y laicos en materias jurídicas que conociendo la doctrina y la jurisprudencia puedan salir al encuentro de aquellos fieles que reuniendo los requisitos establecidos por la ley puedan beneficiarse de ella». 
rantía para la fe de los fieles. De allí la importancia en la preparación de los prelados.

Es necesario superar la tentación de dejar las causas en las manos del Vicario judicial, del asesor o del instructor, como también confiarse ciegamente de los expertos sin asumir una propia posición. Efectivamente, el Obispo llamado a juzgar los fieles que están encomendados a su cuidado, por respeto a ellos, a la Iglesia y al sacramento mismo del matrimonio, no puede enajenarse de la responsabilidad de formarse el propio juicio de frente a la causa que tiene delante de sus ojos. Puede ser que no posea una específica formación jurídica o canónica -que por otra parte adquirirá con el paso del tiempo, la experiencia y la formación permanente-, pero sí una capacidad personal de juicio y los instrumentos formativos que han sido evaluados como idóneos para ser llamados al orden episcopal ${ }^{69}$.

Es claro que de esta dificultad se desprende una segunda: la desaplicación de las normas por falta de tiempo, no por falta de conocimiento. En este sentido, conviene recordar que el peso del proceso breve no va colocado en las manos del Obispo sino del Vicario judicial que acoge el libelo de las partes, nombrando sea el instructor que el asesor ${ }^{70}$. Es decir, es el Vicario quien decide la aceptación de la causa y el rito al cual deberá ser adscrito (proceso breve u ordinario ${ }^{71}$; el Instructor es quien procede a recoger las pruebas y determina los términos para la presentación y las observaciones del Defensor del vínculo y, eventualmente de las partes ${ }^{72}$; finalmente los pareceres del Instructor y del Asesor que ayudarán a la decisión final ${ }^{73}$.

El Obispo, en síntesis, recibe el conjunto probatorio y es llamado a expresar, con la autoridad que le pertenece, un juicio «personal» sobre la causa según la certeza moral que haya adquirido: o la sentencia favorable o el reenvío al examen ordinario ${ }^{74}$, interviniendo exclusivamente en la fase decisoria del proceso. Ahora bien, como recuerda Heredia, no existe algún impedimento

${ }^{69}$ Cfr. $C I C$, can. $331 \$ 1,5^{\circ}$; cfr. CIC-1917, can. $378 \$ 1,5^{\circ}$.

${ }^{70}$ Cfr. Francisco PP, Mot. Prop. Mitis Iudex Dominus Iesus, can. 1685: «El Vicario judicial, con el mismo decreto con el que determina la fórmula de dudas, nombre el instructor y el asesor, y cite para la sesión, que deberá celebrarse conforme el can. 1686, no más allá de treinta días, a todos aquellos que deben participar».

${ }^{71}$ Cfr. IDEM, can. $1676 \$ \$ 1.3-4 ; 1685$; Reglas de procedimiento para tratar las causas de nulidad de matrimonio, art. 15.

72 Cfr. IDEM, can. 1686.

73 Cfr. IDEM, can. $1687 \$ 1$.

${ }^{74}$ Cfr. IDEM, can. $1687 \$ 1$. 
que el Obispo, alcanzada la certeza moral, disponga que sea uno de sus colaboradores a escribir la sentencia si bien siempre ella deberá ser firmada por el Obispo $^{75}$, ateniéndose a cuanto indicado en el Subsidio aplicativo ${ }^{76}$.

A la luz de cuanto hemos expuesto, creo que la potestad judicial del Obispo, así como lo requiere el Motu proprio Mitis Iudex Dominus Iesus, nos ponga de frente, más que a un conjunto de dificultades, a una importante cantidad de posibilidades y desafíos. Será el tiempo, la experiencia y la sana creatividad a dar respuestas nuevas a las situaciones que los fieles viven y por las cuales recurren a la justicia de los tribunales diocesanos, reforzando la capitalidad del Obispo en su función de juez y favoreciendo una jurisprudencia desarrollada a la luz de esta reforma.

${ }_{75}$ Cfr. F. Heredia Esteban, El proceso más breve ante el Obispo, 118.

76 Tribunal Apostólico de la Rota Romana, Subsidio aplicativo del Motu proprio Mitis Iudex Dominus Iesus, 41-42: «La sentencia debe ser firmada personalmente por el Obispo (pero puede ser redactada, por ejemplo, por el Asesor o por el propio Instructor)». 


\section{Bibliografía}

Concilio de Trento, Decreto de reforma, Sesión XXIV, 11 nov. 1563, canon XX, en Conciliorum Oecumenicorum Decreta, EDB, Bologna 1991, 772-773. (Traducción personal al castellano).

CONGREGACIÓN PARA LOS OBISPOS, Directorio Apostolorum succesores: para el ministerio pastoral de los obispos, 22 feb. 2004, LEV, Ciudad del Vaticano 2004.

Del Pozzo, M., Il processo matrimoniale più breve davanti al Vescovo, Roma 2016. (Traducción personal al castellano).

Francisco PP, M. Pr. Mitis Iudex Dominis Iesus, Roma, 15 agosto 2015, en https://w2.vatican.va/content/francesco/es/motu_proprio/documents/papa-francesco-motu-proprio_20150815_mitis-iudex-dominus-iesus.html.

—, M. Pr. Mitis et misericors Iesus, Roma, 15 agosto 2015, en https://w2.vatican.va/content/francesco/it/motu_proprio/documents/papa-francescomotu-proprio_20150815_mitis-et-misericors-iesus.html. (Traducción personal al castellano).

—, Exhortación apostólica postsinodal Amoris laetitia, Roma, 19 marzo 2016.

Heredia Esteban, F., El proceso más breve ante el Obispo, Anuario de derecho canónico 5, Supl. (octubre 2016) 97-122.

JuAN PABLO PP. II, Exhortación apostólica postsinodal Pastores gregis: sobre el Obispo servidor del evangelio de Jesucristo para la esperanza del mundo, Roma, 16 octubre 2003, en http://w2.vatican.va/content/john-paulii/es/apost_exhortations/documents/hf_jp-ii_exh_20031016_pastores-gregis.html.

—, Discurso a la Rota Romana, 29 enero 2005, n. 4, en http://w2.vatican.va/ content/john-paul-ii/es/speeches/2005/january/documents/hf_jp-ii_spe_ 20050129_roman-rota.html.

La riforma dei processi matrimoniali di Papa Francesco. Una guida per tutti, a cura della Redazione di Quaderni di diritto ecclesiale, Milano 2016. (Traducción personal al castellano).

Llobel, J., Questioni comuni ai tre processi del M. P. «Mitis Iudex», Relazione al Seminario di studio «La riforma operata dal m.p. "Mitis Iudex"», LUMSA, Roma, 30 novembre 2015, en http://www.consotiatio.org/repository/Llobell_Lumsa.pdf. (Traducción personal al castellano).

Moneta, P., La dinamica processuale nel m.p. «Mitis Iudex», Seminario di studio presso la Lumsa, Roma, 30 de octubre 2015, en http://consotiatio.org/repository/Moneta_Lumsa.pdf (Traducción personal al castellano). 
PINTO, P. V., La riforma del processo matrimoniale per la dichiarazione di nullità, en L'Osservatore Romano, 8 de septiembre 2015 (http://www.osservatoreromano.va/it/news/la-riforma-del-processo-matrimoniale-la-dichiarazi\#). (Traducción personal al castellano).

—, Entrevista Esperanza sin miedos, en L'Osservatore Romano, edición semanal en lengua española, 7 de octubre 2015 (http://www.osservatoreromano.va/ es/news/esperanza-sin-miedos).

Pontificio Consiglio per l'INTERPRetazione dei Testi Legislativi, Istr. Dignitas connubii, 25 enero 2005, Roma 2005.

Posidio, Vita de San Agustín, en http://www.augustinus.it/spagnolo/vita/possidio.htm.

SABBARESE, L., Il processo più breve: condizione per la sua introduzione, procedura, decisione, en Tra rinnovamento e continuità. Le riforme introdotte dal motu proprio Mitis Iudex Dominus Iesus, Roma 2016, 39-58. (Traducción personal al castellano).

SaCra Congregación Para la Disciplina de los SaCramentos, Instr. Provida Mater Ecclesiae, 15 de agosto 1936, AAS 28 (1936) 313-361.

San Agustín, Confesiones, Libro VI, cap. 3, traducción de Ángel Custodio Vega Rodríguez (http://www.augustinus.it/spagnolo/confessioni/conf_06.htm).

—, Enarratione in Psalmos 118.24.3, en www.agustin.it/spagnolo/esposizioni_salmi/index2.htm.

SíNODO DE OBISPOS, III Asamblea general extraordinaria: Los desafíos pastorales de la familia en el contexto de la evangelización, Instrumentum laboris, Ciudad del Vaticano 2014, en http://www.vatican.va/roman_curia/synod/documents/rc_synod_doc_20140626_instrumentum-laboris-familia_sp.html.

—, XIV Asamblea general ordinaria, La vocación y la misión de la familia en la Iglesia y en el mundo contemporáneo, Instrumentum laboris, Ciudad del Vaticano 2015, en http://www.vatican.va/roman_curia/synod/documents/rc_ synod_doc_20150623_instrumentum-xiv-assembly_sp.html.

—, XIV Asamblea general ordinaria, La vocación y la misión de la familia en la Iglesia y en el mundo contemporáneo, Relación final, Ciudad del Vaticano, 24 de ooctubre de 2015, en http://www.vatican.va/roman_curia/synod/documents/rc_synod_doc_20151026_relazione-finale-xiv-assemblea_sp.html.

Storia della Chiesa, H. JEDIN (dir.), vol. II, Milán 1992. (Traducción personal al castellano).

Tribunal Apostólico de la Rota Romana, Subsidio aplicativo del Motu proprio Mitis Iudex Dominus Iesus, Ciudad del Vaticano 2016. 
